\section{Prohexadione-Ca Affects Vegetative Growth of the Rejuvenated Shoots in Walnut Trees}

\author{
Anita Solar ${ }^{1}$ \\ Department of Agronomy, Biotechnical Faculty, University of Ljubljana, \\ Experimental Field for Nut Crops, Vinarska 14, SI-2000 Maribor, Slovenia
}

Jerneja Jakopič, Robert Veberič, and Franci Štampar

Department of Agronomy, Biotechnical Faculty, University of Ljubljana, Jamnikarjeva 101, SI-1000 Ljubljana, Slovenia

Additional index words. plant growth regulator, shoot elongation, growth flushes, radial growth, scion wood, wood/pith ratio, grafting success, Juglans regia L.

Abstract. Prohexadione-calcium (ProCa), formulated as Regalis, was tested as a vegetative growth inhibitor in rejuvenated annual shoots of 14-year-old mother trees in the 'Franquette' walnut cultivar. ProCa was applied three times during growing seasons in 2005 (Y5) and 2006 (Y6). This was during the second half of spring growth flush, the resting phase between the first and second growth flushes, and in the middle of summer growth flush. As a result, treated shoots in the upper part of the canopy were shorter than untreated ones during the whole growing season in both years. In Y5, two treatments of ProCa $\left(250 \mathrm{mg} \cdot \mathrm{L}^{-1}\right)$, applied until the middle of June, inhibited shoot elongation during summer growth, which was the main purpose of the experiment. The reduction of shoot elongation was between $18 \%$ [lower shoots in the canopy (LS)] and 33\% [upper shoots (US)]. After three ProCa applications, also the final length of the shoots was reduced by $5 \%$ (US) and $18 \%$ (LS). In Y6, when $100 \mathrm{mg} \cdot \mathrm{L}^{-1}$ of ProCa had been used, strong reduction (24\%) was observed only in US after two treatments. Summer growth was not reduced, probably as a result of an interaction between lower concentration of ProCa and stress caused by a water deficit and extremely high temperatures during the summer. On the base of the shoots, three treatments of ProCa $\left(100 \mathrm{mg} \cdot \mathrm{L}^{-1}\right)$ in Y6 increased the ratio between wood and pith and, consequently, increased the quality and uniformity of the scion wood. Further research into additional cultivars and ProCa concentrations is recommended to optimize the terms of application.

Cultivating walnuts is only economically efficient when grafted material is planted in orchards. In comparison with the spreading of walnut seedlings, common in many European countries, grafted trees are much more precocious and give twice or even a three times higher yield (Germain, 1997; McGranahan and Leslie, 1991; Szentivanyi, 1990). In several European countries where walnuts are commercially grown, grafted trees were first planted some 30 to 40 years ago. The propagation method, applied in many nurseries, is "omega" grafting by machine performed in the first half of April. One-yearold seedlings, the progeny of selected mother plants from domestic populations of common walnut, are most frequently used as rootstocks. In addition to well-rooted rootstock, the quality of the scion wood strongly influences grafting's success. A short section of a 1 -year-old shoot with two dormant buds is

Received for publication 15 July 2007. Accepted for publication 31 Oct. 2007.

This work is part of the program Horticulture No. P4-0013-0481 granted by the Slovenian Ministry of Higher Education, Science and Technology.

${ }^{1}$ To whom reprint requests should be addressed; e-mail anita.solar@email.si to $4: 1$. Such shoots are normally developed only on well-structured mother trees, between 3 and $4 \mathrm{~m}$ high, with a trunk of $1 \mathrm{~m}$. They have to have strong central axes. Lateral branches that represent "heads," i.e., the basis for further rejuvenated shoots, have to be spirally arranged around the central axis.

When mother plants are still young and in some years, particularly when the spring is extra rainy and warm, the new shoots grow too vigorously. They become too strong, have a low number of nodes, too long internodes, a smaller number of vegetative buds, and unsuitable wood:pith ratio. Consequently, they are less suitable as a scion wood for grafting, and for the nurserymen, they represent mother material of lower value.

In such years, a particular method is needed for reducing vegetative growth, thus helping the nurseryman to achieve quality rejuvenated shoots for scions.

Over the last decade in deciduous fruit tree production, prohexadione-calcium (ProCa) has been introduced as a plant bioregulator to control vegetative and cropping performance. ProCa, an acylcyclohexadione, is a new plant growth retardant that reduces shoot growth by inhibiting the late stages of gibberellin (GA) biosynthesis, e.g., hydroxylation of $\mathrm{GA}_{20}$ to $\mathrm{GA}_{1}$ (Brown et al., 1997; Rademacher, 1993, 2000). ProCa is easily absorbed by leaves and is translocated acropetally, but basipetal movement is limited (Evans et al., 1997). In the plant tissues, it is rapidly metabolized (Evans et al., 1999) and shows benign toxicological and ecotoxicological properties (Rademacher et al., 1998).

There are many reports dealing with ProCa's influence on vegetative growth in pome fruit trees as well as in stone fruit trees. According to Medjdoub et al. (2004), ProCa has been shown to be an effective inhibitor of vegetative growth in 'Smoothee Golden Delicious'/M9, in which terminal and lateral annual shoots were inhibited from the beginning of the growing season. In pears, ProCa reduced the shoot growth of both bearing trees in the orchard and nonbearing scions under greenhouse conditions (Costa et al., 2001). As reported by Smit et al. (2005), in some pear cultivars, shoot growth was reduced by up to $50 \%$. In sweet cherry, short-term reductions in terminal shoot elongation caused by ProCa was reported by Elfving et al. (2003). Until now, no investigations have been carried out concerning nut trees or about applying ProCa to moderate the vegetative growth of mother trees, which are severely pruned annually.

This study was designed to evaluate the potential of ProCa for the reduction of shoot growth in mother walnut trees. During two experiments conducted in 2005 and 2006, we tried to reduce vegetative growth of rejuvenated annual shoots and to increase their wood:pith ratio with the aim of improving the quality and uniformity of the scion wood.

\section{Materials and Methods}

The research was conducted in Maribor, NE Slovenia, in an experimental orchard of the Biotechnical Faculty, Agronomy Department. Fourteen-year-old mother trees of the cultivar 'Franquette' planted in a single row, $2.5 \mathrm{~m}$ apart from each other, were included in the trial. The trees were not irrigated. They form a strong central leader with eight to 10 first-order branches that are spirally arranged from $1 \mathrm{~m}$ above the ground toward the top of the central axis. Because the trees were 6 years old, their primary as well as secondary 
branches had been cut "on a head" at the end of each winter to stimulate the development of rejuvenated annual shoots for scion wood.

The trial encompassed single tree plots in a randomized complete block design with four replications. There was one nontreated tree between each treated and nontreated tree to signify separation. The trees were sprayed with ProCa formulated as Regalis (BASF AG, Ludwigshafen, Germany) (wettable granular with $10 \%$ ProCa) and compared with untreated trees. The spray solution was applied using handgun equipment to runoff to single-tree plots. The investigation was conducted in 2005 (Y5) and 2006 (Y6). In both years, the trees were treated three times during the growing season: first, in the second half of the first growth flush; second, ProCa was applied during the resting phase between the first and second growth flushes; and third, the trees were sprayed in the middle of the second growth flush. In Fall 2006, wood:pith ratio was also calculated in the treated and nontreated shoots.

Expt. 1. In 2005, the trees received an application of ProCa at $250 \mathrm{mg} \cdot \mathrm{L}^{-1}$ on 30 May, 15 June, and again on 27 June. Eight representative shoots per tree were selected for data recording. Four of them were growing in the upper half of the canopy [upper shoots (US)] and another four in the lower half of the canopy [lower shoots (LS)]. In both parts, upper and lower, one selected shoot was oriented toward to the north, one to the south, one to the east, and the last one to the west side. At the time of the first ProCa application, the lower shoots measured $30 \pm 5$ $\mathrm{cm}$ in length, whereas the upper shoots were $40 \pm 5 \mathrm{~cm}$. The shoots lengths and basal diameters were measured 2 weeks after the first ProCa application [15 June (T1)], second on 13 July (T2), and, finally, after leaf fall, on 9 Nov. (T3). In addition, the number of nodes was counted at each sampling date. The length of each shoot was measured using a fabric tape measure, from the base to the top, in centimeters. The diameter was determined using a caliper, as close to the base of the shoot as possible, in millimeters. The nodes were counted from the base of a shoot toward the tip from the first to the last distinguishable node.

Expt. 2. In 2006, ProCa at $100 \mathrm{mg} \cdot \mathrm{L}^{-1}$ was applied on the same trees as in the previous year, beginning on 14 June followed by 28 June and 12 July. The initial length of shoots was 50 to $55 \mathrm{~cm}$ in the upper part of the canopy and 40 to $45 \mathrm{~cm}$ in the lower part. Shoot lengths, basal diameters, and the number of nodes were firstly recorded after two ProCa applications, on 9 July (T1); second, after three ProCa applications, on 9 Aug. (T2); and after leaf fall, on 1 Dec. (T3). At the last sampling date, the shoots were cut, and additional measurements of wood and pith were conducted. The width of the wood and the pith was measured on the shoot's crosssection (Fig. 1). There were two points of measurement: on the base of the shoot, $2 \mathrm{~cm}$ under the first visible vegetative bud, appropriate for budding (b), and halfway along the

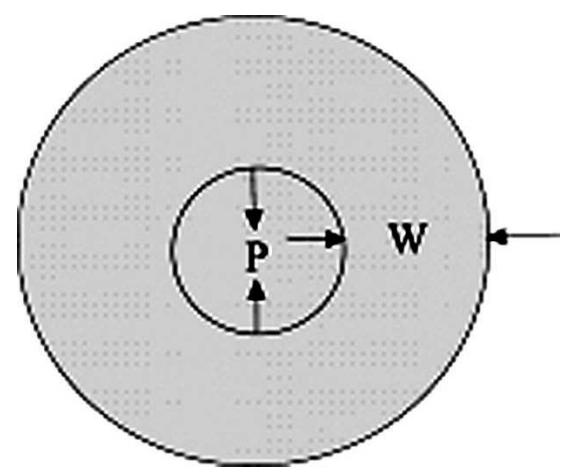

Fig. 1. Cross-section of the rejuvenated annual shoot in walnut. $\mathrm{W}=$ wood; $\mathrm{P}=$ pith.

shoot's length (h). On the basis of wood and pith width, the wood:pith ratio on the shoot base and half of its length were calculated according to the following equation:

$\mathrm{R}(\mathrm{W} / \mathrm{P})=[2 \times$ width of wood $](\mathrm{mm}) /$ width of pith $(\mathrm{mm})$

Statistical analysis. The investigation was evaluated as two independent experiments separated by the years 2005 and 2006. Each of them was a two-factor experiment, i.e., location of the shoot in the canopy, and the date of ProCa applications. The significance of the factors was tested with analysis of variance and the Duncan test at the $95 \%$ confidence level using Statgraphics Plus 4.0 (Manugistics, Rockville, MD).

\section{Results}

Length of shoots. ProCa reduced vegetative growth of rejuvenated shoots in both years of the experiment. In Y5, the first measurements of the shoots were conducted at the same date as ProCa was secondly applied. Significant treatment effects on secondary growth flush as well as the final shoot lengths were observed. At the end of the second growth flush (T2), shoots attained lengths of 86 to $125 \mathrm{~cm}$. At this time, US from the control trees were statistically significantly longer than those from the treated trees. The percentage of US elongation in the time between $\mathrm{T} 2$ and $\mathrm{T} 1$ was 41 in the treated
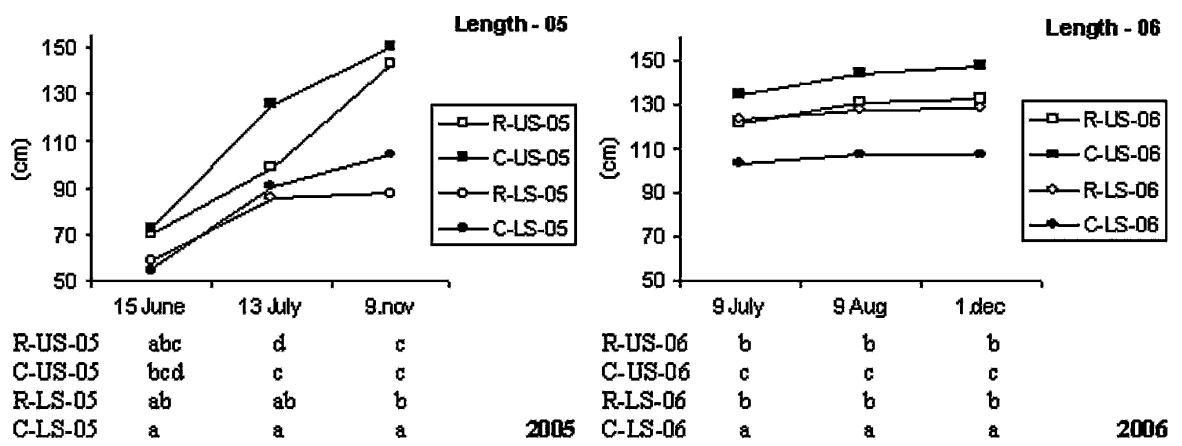

Fig. 2. Length of rejuvenated annual shoots in 'Franquette' walnut trees in 2005 and 2006. $\mathrm{R}=$ Regalis; $\mathrm{C}=$ control; US = upper shoots in the canopy; LS = lower shoots. Means in columns with different letters that are shown under the figure are significantly different according to the Duncan multiple range test $(P \leq 0.05)$ trees compared with 74 in the control trees. Such an influence, but not quite so strong, was also observed in LS, in which the percentage of elongation between $\mathrm{T} 2$ and T1 was 46 for treated trees compared with 64 for untreated trees. At the end of the growing season (T3), the final lengths of the shoots were between $87 \mathrm{~cm}$ and $150 \mathrm{~cm}$. A reduction of shoot length caused by ProCa was evident in both parts of the tree canopies.

In Y6, the first measurement of the shoots was done after two applications of ProCa. It inhibited mainly spring extension of the shoots. The spring growth unit of treated shoots attained lengths of $122 \mathrm{~cm}$ to $134 \mathrm{~cm}$ (Fig. 2). The longest shoots were grown in the upper part of the canopies in untreated trees. In treated trees, LS were practically equal to US. The statistically significant inhibition effect of ProCa was observed in US during the whole growing season (Fig. 2). LS grown on treated trees were longer than the control at all three measuring dates.

Basal diameter. In basal diameter (BD), an opposite response of shoots to ProCa their length. In the upper parts of the canopies, an increasing influence on BD was noted at the first and the second measuring dates in both years. Treated US attained larger BD than the control (Fig. 3). In the stage of leaf fall (T3), an accelerating impact of ProCa was evident in US as well as LS from Y6, whereas in Y5, all the treated shoots had thinner BD than the control ones. Basal diameter increment of the untreated shoots exceeded the one calculated for treated shoots, regardless of which part of the canopy and the time of ProCa application. The largest difference in $\mathrm{BD}$ was observed in the time between $\mathrm{T} 3$ and $\mathrm{T} 2$ in $\mathrm{Y} 5$, when BD of control LS increased by $39 \%$ compared with treated LS with $20 \%$ of BD increment.

Number of nodes. The results show that ProCa increased the number of nodes of rejuvenated shoots. This influence was observed after spring growth flush (T1) and at the end of Y5 as well as during the whole season of Y6 (Fig. 4). The difference was statistically significant in the case of US after three ProCa applications in Y6 measured at applications was observed compared with 

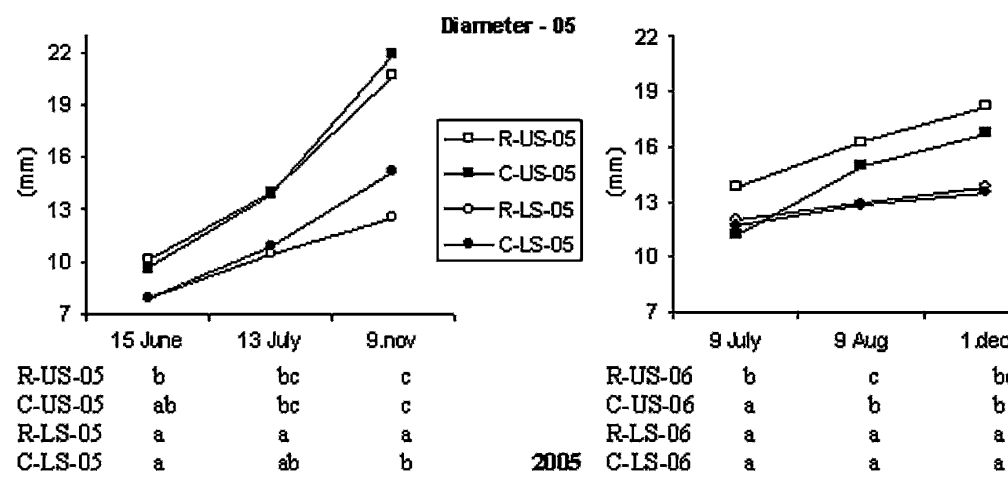

Fig. 3. Basal diameter of rejuvenated annual shoots in 'Franquette' walnut trees in 2005 and 2006. $R=$ Regalis; $\mathrm{C}=$ control; US = upper shoots in the canopy; LS = lower shoots. Means in columns with different letters that are shown under the figure are significantly different according to the Duncan multiple range test $(P \leq 0.05)$.
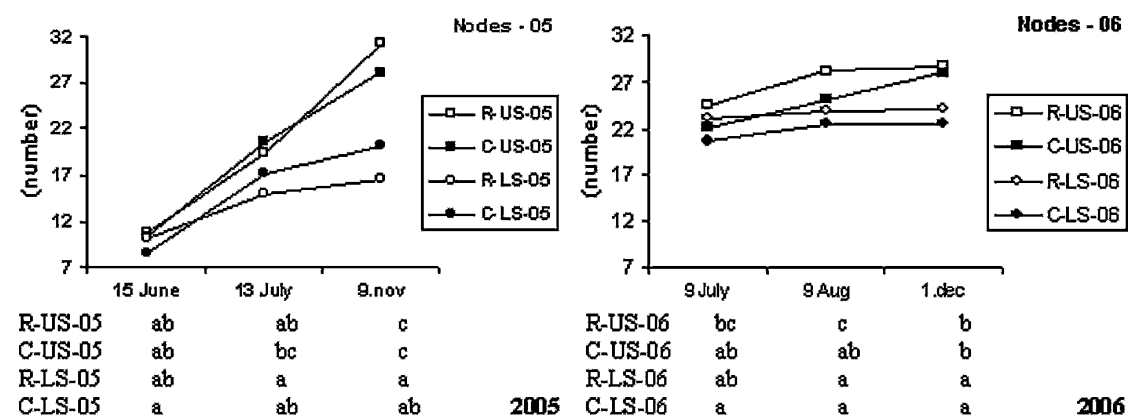

Fig. 4. Number of nodes of rejuvenated annual shoots in 'Franquette' walnut trees in 2005 and 2006. R= Regalis; $\mathrm{C}=$ control; US = upper shoots in the canopy; LS = lower shoots. Means in columns with different letters that are shown under the figure are significantly different according to the Duncan multiple range test $(P \leq 0.05)$.

T2. In T1 of Y5 as well as in all three measuring dates of $\mathrm{Y} 6$, the treated shoots had more nodes compared with control shoots in both parts of the canopies. At the end of Y5, treated US had more nodes than control shoots, whereas in LS, the ratio between treated and untreated shoots was the opposite.

Wood:pith ratio. The effect of ProCa on wood:pith (W:P) ratio was measured at the end of the growing season Y6. Three treatments, applied until the middle of July, statistically significantly affected W:P ratio in the base of the shoots by increasing it from 2.95 to 3.44 (US) and from 2.14 to 2.71 (LS). This was between 2.3 and three times larger than W:P measured at midlength of the shoots (Fig. 5). Here, no effect was observed.

\section{Discussion}

In our experiment, we tested ProCa, formulated as Regalis, to reduce the growth vigor of the rejuvenated annual shoots and to increase their $\mathrm{W}: \mathrm{P}$ ratio with the aim of improving the quality and uniformity of grafting material in walnut trees. As reported by Cleland (1969), rejuvenated annual shoots from mother plants usually grow very vigorously. Such rapidly growing shoots produce large amounts of gibberellins. Therefore, inhibitors of gibberellin biosynthesis such as ProCa potentially retard growth and

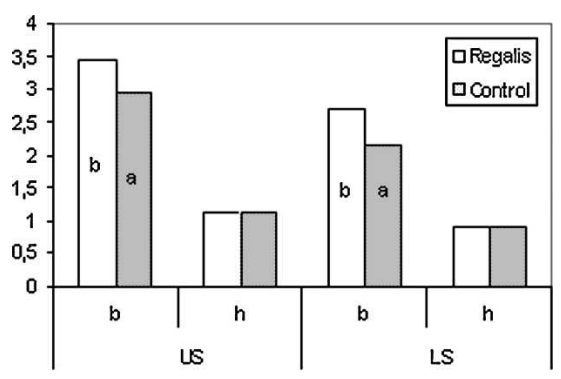

Fig. 5. Wood:pith ratio in rejuvenated annual shoots measured at the base (b) and at halfway of the shoot's length (h) in 'Franquette' walnut trees as affected by prohexadione-calcium. $\mathrm{US}=$ upper shoots in the canopy; LS = lower shoots. Different letters (a, b) in columns indicate statistically significant differences between the treatments.

improve plant productivity or performance (Rademacher, 1991).

The results show that ProCa could be a useful growth inhibitor in walnut mother trees. Different patterns of vegetative growth reduction were observed after ProCa applications. The magnitude of a response depended on the position of the shoots in the canopy (upper or lower halves of the canopy), on the developmental stages of shoots at the time of spraying as well as on ProCa concentration. A similar role of the chemical was proved in some pome and stone fruit trees by Greene (1999), Medjdoub et al. (2004), Costa et al. (2001), Smit et al. (2005), and Elfving et al. (2003).

A reduction in the second (summer) growth flush of the shoots, the main purpose of our study, was clearly observed in Y5 when ProCa was used in a $250-\mathrm{mg} \cdot \mathrm{L}^{-1}$ concentration. After two applications, upper shoots were reduced by $33 \%$ of their length, whereas the lower treated shoots were $18 \%$ shorter than the untreated ones. These reductions were similar to those reported by Medjdoub et al. (2004). They reached an inhibition level of $27 \%$ and $36 \%$ of the control, when ProCa at 200 and $400 \mathrm{mg} \cdot \mathrm{L}^{-1}$ were applied to 'Smoothee Golden Delicious' apple trees.

At the same time when decreasing the lengths of shoots, their BDs were increased in the US and LS regardless of the year and the treatment (Fig. 3). The highest difference regarding increase between the control and the treated shoots was observed in US at the end of season Y5, when the untreated shoots increased twice the BD thickness than the treated ones. It is a fact in bearing walnut tree that the length of the annual shoot is positively correlated to its BD (Solar et al., 2003, 2006). Depending on fruiting behavior and the year, it could be expected that BD will increase by $0.5 \mathrm{~mm}$ to $1.3 \mathrm{~mm}$ if the shoot elongates by $10 \mathrm{~cm}$ (Solar et al., 2006). In the nonbearing trees used in our experiment, in Y5, the difference in elongation of the second growth unit between the control and treated shoots was greater $(33 \%)$ than the difference in $\mathrm{BD}$ increment $(6 \%)$ for the same shoots. A possible explanation of intensive radial growth was the number of nodes that increased during the seasons (Fig. 4). New leaves inserted on the additional nodes probably increased total photosynthetic activity of the shoots.

It seemed that seasonal dynamic of shoot formation, partly influenced by weather conditions during the growing season, also affected the response of shoots to ProCa application. In Y5, spring growth lasted from the bud-breaking date until the middle of June. It resulted in rejuvenated shoots of 70 $\mathrm{cm}$ to $72 \mathrm{~cm}$ (US) and $55 \mathrm{~cm}$ to $59 \mathrm{~cm}$ (LS). Considering the initial length of both shoots, the treated and control, was $40 \pm 5 \mathrm{~cm}$ (US) and $30 \pm 5 \mathrm{~cm}$ (LS), respectively, there was no inhibiting effect of ProCa on spring growth flush. In Y6, primary growth started $4 \mathrm{~d}$ later than in Y5 as a result of very cold weather during late winter and early spring with $1.9^{\circ} \mathrm{C}$ under the corresponded means for the period 1961 to 1990 . Despite this, further development was much more intensive because of the enormous precipitation observed in May and June, when more than $50 \mathrm{~mm}$ above the long-term mean values was measured in Maribor. Additionally, the second and third decades of June were extremely warm with $4.8{ }^{\circ} \mathrm{C}$ above the 1961 to 1990 average temperatures. For these reasons, the primary growth flush was prolonged to the end of June. Rejuvenated shoots attained 
almost twice the length of the year before. An inhibition affect by ProCa was observed only in the upper part of the canopy. Regarding the initial shoot length of $50 \mathrm{~cm}$ to $55 \mathrm{~cm}$, the treated shoots prolonged for $67 \mathrm{~cm}$ to $72 \mathrm{~cm}$ in comparison with the control shoots, which increased in length for $79 \mathrm{~cm}$ to $84 \mathrm{~cm}$. The second growth flush starting in the first decade of July was very weak as a result of extremely high temperatures $\left(4{ }^{\circ} \mathrm{C}\right.$ above 1961 to 1990 mean values) and a strong drought ( $46 \%$ of long-term average rainfall). In the upper part of the canopy, elongation of the treated and control shoots in the period (T2-T1) was very low and almost equal, whereas in the lower canopy, elongation of control shoots insignificantly reached over the treated ones. It is possible that water stress that influenced shoot elongation also hides ProCa effect like in the young apple trees reported by Owens and Stover (1999). Another reason for weaker shoot growth inhibition could be found in the lower concentration of ProCa $\left(100 \mathrm{mg} \cdot \mathrm{L}^{-1}\right)$ used in $\mathrm{Y} 6$. To confirm this hypothesis, trials with different ProCa concentrations should be conducted in the future on walnut trees.

When we compared the final length of the rejuvenated shoots, we saw that the control upper shoots were only 5\% (Y5) and $12 \%$ (Y6) longer than the treated ones. In the lower shoots, the difference was $18 \%$ (Y5) and $16 \%$ (Y6), respectively. It has to be stressed that in $\mathrm{Y} 6$, the difference between treated and control shoots was opposite; untreated shoots were $16 \%$ longer than treated ones.

In Y5, a reduction of second growth flush was clearly expressed. In this year, the initial shoot length was $10 \mathrm{~cm}$ to $15 \mathrm{~cm}$ smaller than in Y6, and strong inhibition of vegetative growth could be the result of greater tissue sensitivity in the early treatment, which was in agreement with Unrath (1999). The inhibiting effect of ProCa was maintained through the season only in LS. It is possible that there was an interaction between ProCa and weak light environment in the lower part of the canopy. In the upper canopy, shoot regrowth appeared after the third ProCa application and the growth continued all summer until the end of August. In Y6, we observed only strong inhibition of spring growth, which could be explained by the rapid metabolism of ProCa caused by intensive growth of shoots. Later in the season when the trees were under water deficit pressure, the extension of shoot length was very weak in both the treated and control trees, and very weak regrowth after multiple ProCa applications appeared. These results are in agreement with Miller (2002) who said that the level of shoot regrowth after ProCa application also depends on weather conditions and not only on the concentration and date of application.

After 2 years of experiments, we can say that in walnut, lower concentration of ProCa $\left(100 \mathrm{mg} \cdot \mathrm{L}^{-1}\right)$ can reduce only spring growth of the rejuvenated shoots even if it was applied twice in a short time. When we want to reduce summer growth of the shoots, which was the main aim of our investigation, at least two ProCa applications at $250 \mathrm{mg} \cdot \mathrm{L}^{-1}$ are needed. These results are only partly in agreement with Unrath (1999), who reported that multiple, low-rate applications are more effective in the control of vegetative growth in apple trees than single, high-rate treatment.

An important aim of this study was to ascertain whether ProCa could be implemented in scion wood production to improve their quality, i.e., to have shoots with an appropriate ratio between wood and pith, and high numbers of buds useful for budding. The results show that ProCa statistically significantly affected the W:P ratio of rejuvenated shoots (Fig. 5). At their base, the treated upper shoots had $17 \%$ thicker wood and a better W:P ratio than the control ones. In the lower part of the canopy, the difference in thickness of wood between the treated and untreated shoots was $27 \%$. The treated LS also had better a $\mathrm{W}: \mathrm{P}$ ratio than the control ones. This is beneficial for budwood and ensures more efficient grafting.

In Y6, the treated upper shoots had significantly more nodes per spring growth unit than the control ones (Fig. 4). It means that the treated shoot could be cut into more scion woods with two vegetative buds for each than the untreated shoot. Consequently, more grafted plants could be made from the same number of rejuvenated shoots when only a number of nodes and corresponding buds per shoot length are taken into account .

In conclusion, it is clear that ProCa could be used as an inhibitor for the vegetative growth of rejuvenated annual shoots in 'Franquette' mother trees. Further research is needed to optimize the terms of application. Concentrations of ProCa, needed for effective shoot growth control, are affected by location and climate as well as cultivar response (Autio et al., 2006; Basak and Rademacher, 2000; Bubab et al., 2003; Elfving et al., 2003; Smit et al., 2005). Therefore, investigations should be extended to one additional location using different ProCa concentrations and to two or three of those walnut cultivars frequently planted in commercial orchards.

\section{Literature Cited}

Autio, W.R., J. Krupa, J.M. Clements, and D.W. Greene. 2006. Using naphthalene acetic acid, prohexadione-Ca, etephon, and scoring to reduce vegetative growth in upper canopy of apple trees. HortScience 41:1030.

Basak, A. and W. Rademacher. 2000. Growth regulation of pome and stone fruit trees by use of prohexadione-Ca. Acta Hort. 514:41-50.

Brown, R.G.S., H. Kawaide, Y.Y. Yang, W Rademacher, and Y. Kamiya. 1997. Daminozide and prohexadione have similar modes of action as inhibitors of the late stages of gibberellin metabolism. Physiol. Plant. 101:309-313.

Bubab, T., L. Foldes, A. Kormany, S. Hauptmann, G. Stammler, and W. Rademacher. 2003. Prohexadione-Ca in apple trees: Control of shoot growth and reduction of fire blight incidence in blossoms and shoots. Journal of Applied Botany $77: 95-102$.

Cleland, R.E. 1969. The gibberellins, p. 49-81. In: M.B. Williams (ed.). Physiology of plant growth and development. McGraw Hill, Maidenhead, Berkshire, UK.

Costa, G., C. Andreotti, F. Bucchi, E. Sabatini, C. Bazzi, and S. Malaguti. 2001. Prohexadione-Ca (Apogee $\left.{ }^{\circledR}\right)$ : Growth regulation and reduced fire blight incidence in pear. HortScience 36:931-933.

Elfving, D.C., G.A. Lang, and D.B. Visser. 2003. Prohexadione-Ca and ethephon reduce shoot growth and increase flowering in young, vigorous sweet cherry trees. HortScience 38 : 293-298.

Evans, R.R., J.R. Evans, and W. Rademacher. 1997. Prohexadione calcium for suppression of vegetative growth in eastern apples. Acta Hort. 451:663-666.

Germain, E. 1997. Genetic improvement of the Persian walnut (Juglans regia L.). Acta Hort. 442:21-31

Greene, D.W. 1999. Tree growth management and fruit quality of apple trees treated with prohexadione-calcium (BAS 125). HortScience 34: 1209-1212.

McGranahan, G.H. and C. Leslie. 1991. Walnuts (Juglans), p. 907-951. In: Moore, J.N. and J. R. Ballington Jr. (eds.). Genetic resources of temperate fruit and nut crops, part 2. ISHS, Wageningen, The Netherlands.

Medjdoub, R., J. Val, and A. Blanco. 2004 Prohexadione-Ca inhibits vegetative growth of 'Smoothee Golden Delicious' apple trees. Sci. Hort. 101:243-253.

Miller, S.S. 2002. Prohexadione-calcium control vegetative shoot growth in apple. J. Tree Fruit Prod. 3:11-28.

Owens, C.L. and E. Stover. 1999. Vegetative growth and flowering in young apple trees in response to prohexadione-calcium. HortScience 34:1194-1196.

Rademacher, W. 1991. Inhibitors of gibberellin biosynthesis: Applications in agriculture and horticulture, p. 296-310. In: Tahahaski, N., B.O. Phinney, and J. MacMillan (eds.) Springer-Verlag, New York

Rademacher, W. 1993. On the mode of action of acylcyclohexanediones - A new type of plantgrowth retardant with possible relationship to daminozide. Acta Hort. 329:31-34.

Rademacher, W. 2000. Growth retardants: Effects on giberellin biosynthesis and other metabolic pathways. Annu. Rev. Plant Physiol. Plant Mol. Biol. 51:501-531.

Rademacher, W., M. Krauss, P. Hoeppner, and J.R. Evans. 1998. Prohexadione-Ca-A new bioregulator for the control of vegetative growth in apple. Data Report APE/HF 19984296RAD. BASF Agricultural Center, 67114 Limburgerhof, Germany.

Smit, M., J.J. Meintjes, G. Jacobs, P.J.C. Stassen, and K.I. Theron. 2005. Shoot growth control of pear trees (Pyrus communis L.) with prohexadione-calcium. Sci. Hort. 106:515-529.

Solar, A., A. Ivančič, and F. Stampar. 2003. Morphometric characteristics of fruit bearing shoots in persian Walnut (Juglans regia $\mathrm{L}$.) Potential selection criteria for breeding. European Journal of Horticultural Science 68:86-92.

Solar, A., M. Solar, and F. Štampar. 2006. Stability of the annual shoot diameter in Persian walnut. A case of different branching pattern, fruiting habit and the year. Trees - Structure and Function 20:449-459.

Szentivanyi, P. 1990. Breeding early fruiting, high producing walnut cultivars leafing after late spring frosts. Acta Hort. 284:175-182.

Unrath, C.R. 1999. Prohexadione-Ca: A promising chemical for control vegetative growth in apples. HortScience 34:1197-1200. 